Check for updates

Cite this: RSC Adv., 2018, 8, 11478

\title{
Preparation and properties of a novel covalently bonded energetic boron powder and its composite
}

Received 17th December 2017 Accepted 7th February 2018

DOI: $10.1039 / c 7 r a 13393 f$

rsc.li/rsc-advances

\author{
Baohui Zheng, (D) Tao Liu, Dayuan Gao, Qing Zhu, Shangbin Li, Guan Luo* \\ and Xia Gao
}

Promoting the ignition of boron powders in propellants, explosives and pyrotechnics has been a promising research direction. In this paper, a new strategy for covalently bonded energetic boron powders was designed. Specifically, 2,4-toluene diisocyanate (TDI) and 3-amino-1,2,4-triazole (ATZ) were used as grafting molecules, and then acidification, carbamation and ureylene addition were performed serially on the surface of the boron particles. The reaction conditions were optimized using infrared (IR) spectroscopy and X-ray photoelectron spectroscopy (XPS). At lower temperatures, the addition of carbamation or ureylene can improve the yield and stability of isocyanate and urea groups. The chemical composition, microstructure and surface properties of the boron powders were analyzed with nuclear magnetic resonance (NMR) spectroscopy, scanning electron microscopy (SEM), transmission electron microscopy (TEM) and contact angle (CA) analysis, respectively. The covalent bonding type was confirmed by the typical peaks at 155.7 and $157.5 \mathrm{ppm}$ in the ${ }^{13} \mathrm{C}$ NMR spectra of the intermediate isocyanate-grafting boron powders (TB) and target product triazole-grafting boron powders (TTB). The static water contact angles on the surfaces of TB and TTB were $148.3^{\circ}$ and $37.0^{\circ}$, respectively. Influences of surface modification of boron powders on the rheological properties of boron/hydroxyl-terminated polybutadiene (HTPB) composites were investigated. Moreover, the prepared samples were characterized by thermogravimetry (TG) and differential scanning calorimetry (DSC) to investigate the thermal stability and reaction activity, and the results showed that this grafting strategy could significantly reduce the critical reaction temperature of $\mathrm{B} / \mathrm{KNO}_{3}$. Consequently, it is anticipated that the modified boron powders can potentially be used in propellants, explosives and pyrotechnics with high impulses.

\section{Introduction}

The improvement of impulse properties, which leads to greater cratering and fragmentation effects, requires the addition of metal or metal-like powders in propellants, explosives and pyrotechnics. ${ }^{1}$ A variety of reactive metal or metal-like powders (Al, B, Mg and $\mathrm{Zr}$ ) have been utilized, such as boron-based solid propellants, ${ }^{2}$ aluminum-based high energy explosives ${ }^{3}$ and ignition powders containing boron, magnesium and zirconium. ${ }^{4}$ Among them, boron has higher gravimetric and volumetric heat in comparison with aluminum and many other metal fuels. ${ }^{5}$ Boron has a diverse range of industrial applications in areas such as semiconductors, protective coatings, pyrotechnic flares, high-density fuels, and refractory materials. ${ }^{6}$ Research has shown that compared with aluminum-containing compositions, such as Al/octogen (HMX) and hexogen (RDX)/Al/ ammonium perchlorate (AP), boron-containing ones, B/HMX and $\mathrm{RDX} / \mathrm{Al} / \mathrm{B} / \mathrm{AP}$, have a higher energy. ${ }^{7}$ This indicates that boron is a potential candidate for use as a fuel additive in

Institute of Chemical Materials, China Academy of Engineering Physics, Mianyang 621900, China. E-mail: luoguan@caep.cn; Tel: +86-816-2487915 almost all energetic materials. Nevertheless, the elemental boron particles have a tight coating layer in the form of oxides and hydrates, which reduces the performance as a fuel and leads to inefficient burning. ${ }^{8}$ Moreover, it is extremely difficult for the elemental boron particle to efficiently burn in explosives due to energetic materials such as RDX and HMX having only nanoseconds to detonate, which works against the heat and mass transfer. ${ }^{9}$

Many methods have attempted to promote the ignition and combustion of boron powders, including ultrafine processing, ${ }^{10}$ adding easily combustible metal powders (Li, $\mathrm{Mg}$, Ti and $\mathrm{Zr}$ ), ${ }^{\mathbf{1 1}}$ coating with boron carbide (BC), silicane, lithium fluoride (LiF), glycidyl azide polymer (GAP), and others. ${ }^{12}$ In general, easily combustible metal powders also possess more active property, which results in potential process complexity and security hazards in the preparation and usage of propellants, explosives and pyrotechnics. In addition, the outermost shell is usually separated from the boron core using the adopted coating method, and the particle properties tightly depend on the integrity and structure strength of the coating layer. In view of the above, an intensive study of covalent bonding and chemically stable boron powders is absolutely imperative. 


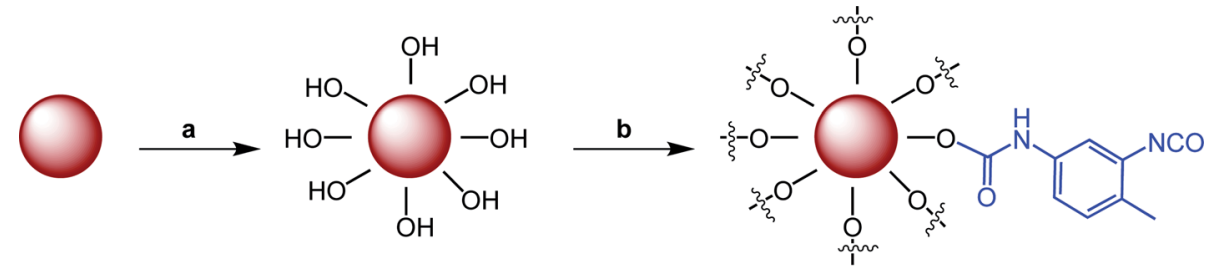

EB

AB

TB

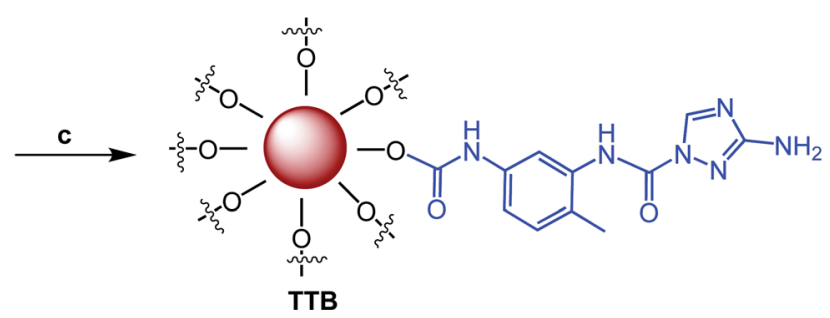

Scheme 1 Synthetic route of the target material with the conditions: (a) $\mathrm{HNO}_{3}$, acetone, r.t., $24 \mathrm{~h}$; (b) TDI, toluene, $\mathrm{DBTL}, 50{ }^{\circ} \mathrm{C}, 5 \mathrm{~h}$; and (c) ATZ, acetonitrile, $40{ }^{\circ} \mathrm{C}, 5 \mathrm{~h}$.

Currently, covalent bonds linking many kinds of metals $(\mathrm{Al}){ }^{13}$ metal oxides $\left(\mathrm{SiO}_{2},{ }^{14} \mathrm{Al}_{2} \mathrm{O}_{3}\right.$ (ref. 15)) and metal nitrides $\left(\mathrm{Si}_{3} \mathrm{~N}_{4}{ }^{16}\right.$ AlN (ref. 17)) have been successfully created. Through a similar measurement, the acid reactive sites on the surface of boron particles can be utilized as the covalent bonding reactive center. It has been reported that surface hydroxyl groups of the boron powders could react with maleic anhydride (MAH), ${ }^{18}$ undecylenic acid ${ }^{19}$ and fatty alcohol. ${ }^{20}$ Thus, through the method of organically modifying the boron surface with some small energetic molecule, it is possible to enable the boron powders with improved ignition properties.

In this article, a novel covalently bonded, energetic boron powder was prepared by acidification, carbamation and ureylene addition reactions. Among the grafting molecules, ATZ is used as the energetic gas generator. ${ }^{21}$ After optimizing the reaction conditions, the properties of the modified boron powders and their composites with potassium nitrate $\left(\mathrm{KNO}_{3}\right)$ were investigated by infrared (IR) spectroscopy, X-ray

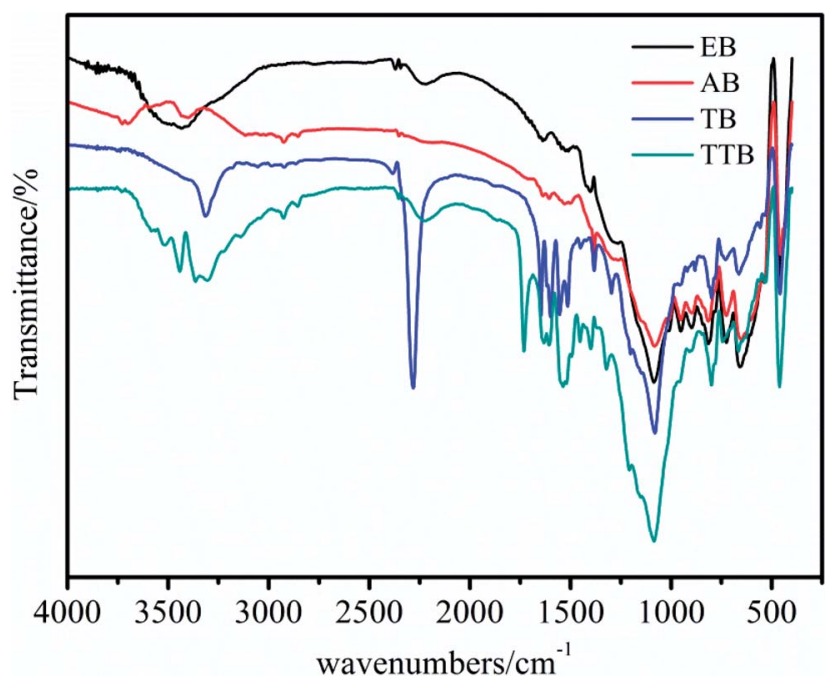

Fig. 1 The IR spectra of the EB, AB, TB and TTB. photoelectron spectroscopy (XPS), solid-state nuclear magnetic resonance (NMR) spectroscopy, scanning electron microscopy (SEM), transmission electron microscopy (TEM), contact angle (CA) analysis, thermogravimetry (TG), and differential scanning calorimetry (DSC).

\section{Experimental section}

\subsection{Materials}

Elemental boron powder (99 wt\%) was purchased from Baoding Pengda Chemical Industry Co., Ltd. (Baoding, China). Nitric acid (65-68 wt\%), dibutyltin dilaurate (DBTL), 2,4-toluene diisocyanate, 3-amino-1,2,4-triazole and potassium nitrate were of analytical purity and obtained from Sinopharm Chemical Reagent Co., Ltd. Acetone containing water at $0.3 \mathrm{wt} \%$ and other reagents used in the presented study were commercially purchased.

\subsection{Characterization}

Infrared (IR) spectra were collected with a Nicolet 6700 FT-IR spectrophotometer using $\mathrm{KBr}$ pellets. X-ray photoelectron spectroscopy (XPS) analysis was conducted with a VG ESCALAB 250 instrument using $\mathrm{Mg}-\mathrm{K} \alpha$ radiation at $200 \mathrm{~W}$. Solid-state nuclear magnetic resonance spectroscopy (NMR) tests were performed on a Brucker Advance III $400 \mathrm{MHz}$. Scanning electron microscopy (SEM) measurements were performed with a ZEISS Ultra 55 scanning electron microscope at an operating voltage of $20 \mathrm{kV}$. Transmission electron microscopy (TEM) analyses were performed on a Zeiss Libra $200 \mathrm{FE}$ (Germany) TEM, with an accelerating voltage of $200 \mathrm{kV}$. The particle size distribution was characterized using a Beckman-Coulter LS 230 laser particle size analyzer. The rheological parameters of B/ HTPB were characterized using an Anton Paar MCR 102 rheometer and parallel plate geometry (PP25, plate diameter $24.978 \mathrm{~mm}$, plate distance $1 \mathrm{~mm}$ ). Thermogravimetry (TG) curves were recorded with a TG-DTA 6200 LAB SYS thermal gravimetric analyzer, and differential scanning calorimetry 
(DSC) was recorded with a TA Q200 instrument from room temperature to $1200{ }^{\circ} \mathrm{C}$ in a nitrogen atmosphere at a heating rate of $20^{\circ} \mathrm{C} \mathrm{min}^{-1}$.

\subsection{Preparation of covalent bonded energetic boron powders}

Grafting on the surface of boron particles was conducted using consecutive condensation reactions between $-\mathrm{OH},-\mathrm{NH}-$ and -NCO groups, as shown in Scheme 1. To endow more hydroxyl groups on the surface of the boron particles, the raw boron particles were treated with concentrated nitric acid in the solvent acetone. The secondary amine in the triazole of ATZ is more active than the primary amine, which was proved by numerous researches, especially in the reaction between 3amino-1,2,4-triazole or its analogs and isocyanates or isothiocyanates. ${ }^{22,23}$ Thus, the intermediate TB reacted with 1 equiv of ATZ and generated the target material TTB with a structure as shown in Scheme 1. In all three steps, the purification of boron powders was only conducted with filtration in this conveniently synthetic route.

In a typical experiment, $20 \mathrm{~g}$ of boron powder and $200 \mathrm{~mL}$ of acetone were placed in a round-bottom flask. After $1.5 \mathrm{~mL}$ of nitric acid was added dropwise, the mixture was stirred for another $24 \mathrm{~h}$ at room temperature. The resultant mixture was filtered and washed twice with $150 \mathrm{~mL}$ acetone, and then approximately $20 \mathrm{~g}$ of the acidified boron powder $(\mathrm{AB})$ was obtained after vacuum drying overnight at room temperature.

Then, $2.0 \mathrm{~g}$ acidified boron powder (AB) was dispersed with $200 \mathrm{~mL}$ anhydrous toluene in a three-neck flask equipped with a condenser and a magnetic stirrer. After that, $0.73 \mathrm{~g}$ of TDI and two drops of DBTL were added into the reaction mixture and left to stir at $50{ }^{\circ} \mathrm{C}$ for $5 \mathrm{~h}$. Finally, the mixture was cooled to room temperature, and treated by filtration through Buchner funnel. The residue was washed with $150 \mathrm{~mL}$ ethyl acetate three times. Approximately $2.20 \mathrm{~g}$ TDI-grafting boron powders (TB) were obtained after vacuum drying overnight at room temperature.

TB $(0.50 \mathrm{~g})$, ATZ $(0.12 \mathrm{~g})$, two drops of DBTL and $50 \mathrm{~mL}$ anhydrous acetonitrile were placed in a three-neck flask equipped with a condenser. The reaction was carried out under vigorous stirring at $40{ }^{\circ} \mathrm{C}$ for $5 \mathrm{~h}$. The mixture was filtered during the warm state, and the residue was washed with $60 \mathrm{~mL}$ ethyl alcohol three times. Then, it was dried under vacuum overnight at room temperature to give approximately $0.48 \mathrm{~g}$ of further ureylene-based product TTB.

\subsection{Preparation of $\mathrm{B} / \mathrm{KNO}_{3}$ composites}

First, $0.50 \mathrm{~g}$ of boron powder, $0.75 \mathrm{~g}$ of potassium nitrate and an additional $0.5 \mathrm{wt} \%$ phenol formaldehyde resin were mixed in a weight ratio of $40: 60: 0.5$ with $20 \mathrm{~mL}$ ethyl alcohol in
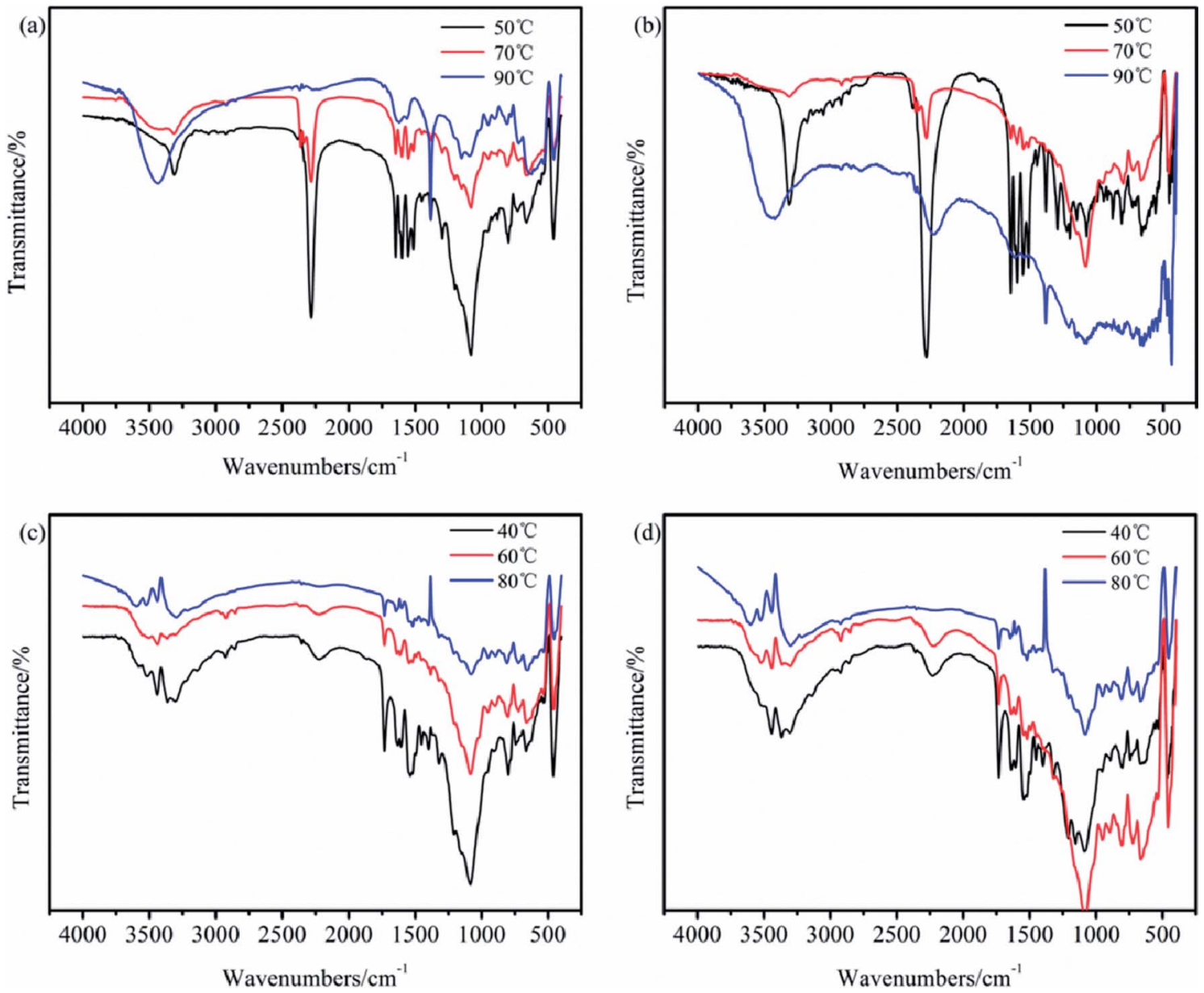

Fig. 2 IR spectra of the TB prepared for (a) $5 \mathrm{~h}$ and (b) $10 \mathrm{~h}$, and the TTB prepared for (c) $5 \mathrm{~h}$ and (d) $10 \mathrm{~h}$ at different temperatures. 

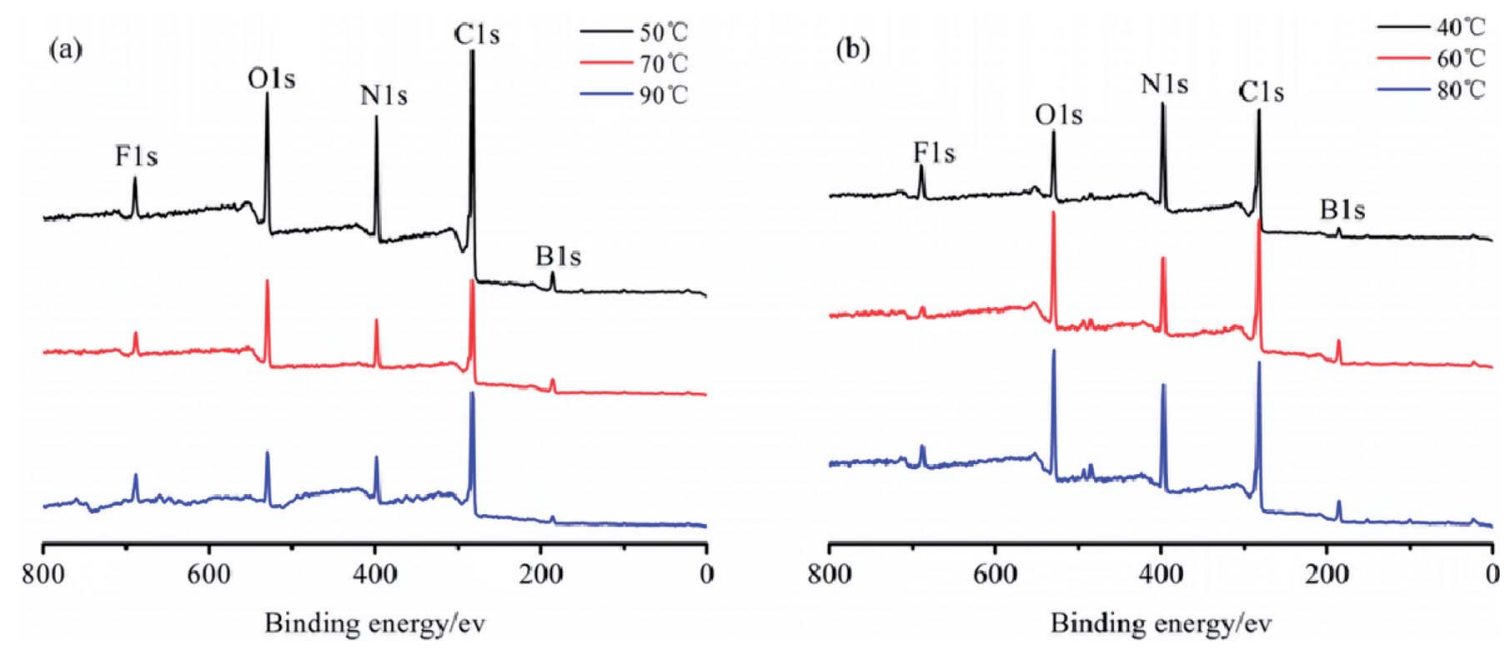

Fig. 3 XPS spectra of (a) TB and (b) TTB prepared for $10 \mathrm{~h}$ at different temperatures.

a beaker. After ultrasonic processing for 20 minutes, the mixture was evaporated at $50{ }^{\circ} \mathrm{C}$ while stirring for $5 \mathrm{~h}$. Then, the sample was vacuum dried overnight at room temperature, and the $\mathrm{B} / \mathrm{KNO}_{3}$ composites were obtained.

\section{Results and discussion}

\subsection{Preparation of TB and TTB}

The hydroxyl and isocyanate groups are crucial reactive sites for the chemical bonding of TDI and ATZ. To confirm that the modification of the boron powders is successful, IR spectra analyses of the samples, including the raw material $\mathrm{EB}$, intermediates $\mathrm{AB}$ and $\mathrm{TB}$, and the target material TTB, were performed, as shown in Fig. 1. According to the above test results, the following can be observed: (1) during the acidification process, the absorption at $3440 \mathrm{~cm}^{-1}$ in the IR spectrum of EB corresponding to the B-B weakened, and the $3410 \mathrm{~cm}^{-1}$ band caused by $\mathrm{O}-\mathrm{H}$ appeared possibly due to the surface $\mathrm{B}_{2} \mathrm{O}_{3}$ reacting with water in the nitric acid and acetone solvent. (2) After the carbamation of $\mathrm{AB}$ at $50{ }^{\circ} \mathrm{C}$ for $5 \mathrm{~h}$, the reactive site $-\mathrm{OH}$ reacted with the $-\mathrm{NCO}$ group from the TDI molecule, generating a new group - NH-COO- and an unreacted - NCO group. Therefore, in the IR spectrum of $\mathrm{TB}$, the band at $3410 \mathrm{~cm}^{-1}$ caused by stretching vibrations of the $\mathrm{O}-\mathrm{H}$ disappeared, and a prominent peak at $2276 \mathrm{~cm}^{-1}$ caused by antisymmetric stretching vibrations of $\mathrm{N}=\mathrm{C}=\mathrm{O}$ appeared. ${ }^{22}$ The bands at 3305,1647 , and $1499-1618 \mathrm{~cm}^{-1}$ could be attributed to the stretching vibrations of $\mathrm{N}-\mathrm{H}, \mathrm{C}=\mathrm{O}$ in $-\mathrm{NH}-\mathrm{COO}-$ group and the benzene framework vibration, respectively. ${ }^{22}$ (3) In the last ureylene addition step at $40{ }^{\circ} \mathrm{C}$ for $5 \mathrm{~h}$, the active sites of $\mathrm{N}=\mathrm{C}=\mathrm{O}$ in the $\mathrm{TB}$ reacted with the $-\mathrm{NH}-$ group in the triazole ring of the ATZ, generating a urea group -NH-CO-N $\mathrm{N}^{\prime}$. In the IR spectrum of the TTB, the peak at $2276 \mathrm{~cm}^{-1}$ corresponding to the $\mathrm{N}=\mathrm{C}=\mathrm{O}$ disappeared, and the emerged peaks at 3364 and $1740 \mathrm{~cm}^{-1}$ could be attributed to the stretching vibrations of $\mathrm{N}-\mathrm{H}$ and $\mathrm{C}=\mathrm{O}$ in the $-\mathrm{NH}-\mathrm{CO}-\mathrm{N}^{\prime}$ group, respectively.

Due to the importance of maintaining the active isocyanate in the intermediate $\mathrm{TB}$, the reaction conditions in the carbamation and ureylene addition steps are essential to optimize. Herein, the IR and XPS spectra were applied as qualitative and semiquantitative research methods to attain better reaction conditions. In the preparation of $\mathrm{TB}$, the effects of the reaction temperature at 50,70 , and $90{ }^{\circ} \mathrm{C}$ and the reaction time for 5, 10, and $15 \mathrm{~h}$ on the structure of TB were studied. The reaction temperatures of 40,60 , and $80^{\circ} \mathrm{C}$ and reaction times of 5,10 , and $15 \mathrm{~h}$ in the preparation of TTB were also investigated.

The IR spectra of TB and TTB samples at various conditions are shown in Fig. 2. It was found that at both $50{ }^{\circ} \mathrm{C}$ and $70{ }^{\circ} \mathrm{C}$, the carbamation was successfully processed because of the predominant peaks attributed to the $\mathrm{N}=\mathrm{C}=\mathrm{O}$ and benzene ring. However, at $90{ }^{\circ} \mathrm{C}$, none of the above-mentioned peaks were found in the IR spectrum, and an additionally peak at $3448 \mathrm{~cm}^{-1}$ was strengthened, which can infer that the introduced TDI on the boron particle surface was thermally decomposed. For the preparation of TTB at different temperatures, the typical absorption characteristic peak at $2276 \mathrm{~cm}^{-1}$ corresponding to the $\mathrm{N}=\mathrm{C}=\mathrm{O}$ disappeared, and the typical absorption peaks at 3364 and $1740 \mathrm{~cm}^{-1}$ were attributed to the $\mathrm{N}-\mathrm{H}$ and $\mathrm{C}=\mathrm{O}$ of the $-\mathrm{NH}-\mathrm{CO}-\mathrm{N}^{\prime}$ group emerged. However, the absorption strength assigned to the $\mathrm{C}=\mathrm{O}$ of the $-\mathrm{NH}-\mathrm{CO}-$ $\mathrm{N}^{\prime}$ relative to the benzene ring tended to decrease at higher temperatures. Therefore, the lower temperature is beneficial to both the carbamation and the ureylene addition reactions.

The elemental analysis of the particle surface was used to evaluate the reaction conditions. The XPS spectra of the TB

Table 1 Elemental content in TB and TTB prepared at different temperatures for $10 \mathrm{~h}$

\begin{tabular}{lrrrrrrr}
\hline & \multicolumn{2}{c}{ Content in TB/\% } & & \multicolumn{3}{c}{ Content in TTB/\% } \\
\cline { 2 - 3 } \cline { 6 - 7 } State & $50{ }^{\circ} \mathrm{C}$ & $70{ }^{\circ} \mathrm{C}$ & $90{ }^{\circ} \mathrm{C}$ & & $40{ }^{\circ} \mathrm{C}$ & $60{ }^{\circ} \mathrm{C}$ & $80{ }^{\circ} \mathrm{C}$ \\
\hline $\mathrm{C} 1 \mathrm{~s}$ & 57.07 & 48.11 & 59.88 & & 46.28 & 46.06 & 43.55 \\
$\mathrm{~N} 1 \mathrm{~s}$ & 17.28 & 13.62 & 12.26 & & 26.03 & 14.45 & 18.71 \\
O1s & 9.25 & 14.23 & 11.26 & & 10.75 & 11.53 & 13.32 \\
B1s & 13.66 & 20.13 & 10.81 & & 11.86 & 25.71 & 21.47 \\
Other & 2.74 & 3.91 & 5.7 & & 5.08 & 2.26 & 2.96
\end{tabular}



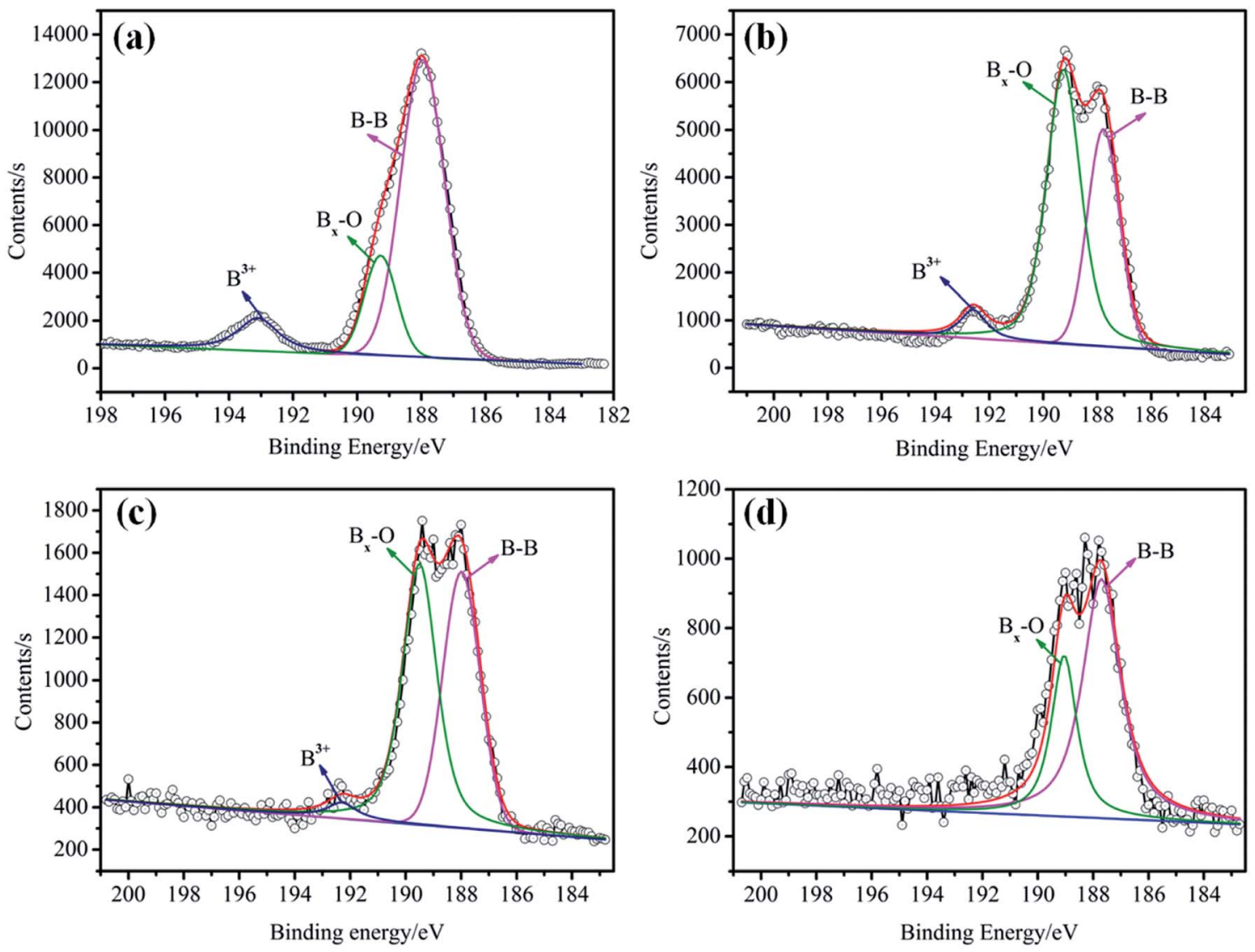

Fig. 4 Enlarged XPS spectra of B 1s for (a) EB, (b) AB, (c) TB and (d) TTB.

prepared at 50,70 , and $90{ }^{\circ} \mathrm{C}$, and TTB prepared at 40,60 , and $80{ }^{\circ} \mathrm{C}$ for $10 \mathrm{~h}$ were shown in Fig. 3 . And the elemental content of the samples were given in Table 1 , which was gained by normalization processing the ratio of characteristic peak area to the sensitivity factor. In Fig. 3, peak from 392 to $402 \mathrm{eV}$ was displayed in the XPS pattern of the $\mathrm{N} 1 \mathrm{~s}$ state, which verified the incorporation of $\mathrm{N}$ from the TDI into the TB particles. In the enlarged XPS spectrum of B 1s in Fig. 4, the main component of $\mathrm{EB}$ at $188.0 \mathrm{eV}$ corresponded to the $\mathrm{B}-\mathrm{B}$ bond, ${ }^{24}$ and the component at $189.4 \mathrm{eV}$ and $193.2 \mathrm{eV}$ was assigned to the $\mathrm{B}-\mathrm{O}$ bond in the suboxide $\left(\mathrm{B}_{x}-\mathrm{O}\right)$ and oxide $\left(\mathrm{B}_{2} \mathrm{O}_{3}\right)$ compounds, respectively. ${ }^{25}$ After acidification, in the enlarged XPS spectrum of $\mathrm{B} 1 \mathrm{~s}$ in $\mathrm{AB}$, the component at $192.6 \mathrm{eV}$ was assigned to the $\mathrm{H}_{3} \mathrm{BO}_{3},{ }^{26}$ and the typical peak at $189.4 \mathrm{eV}$ was assigned to the
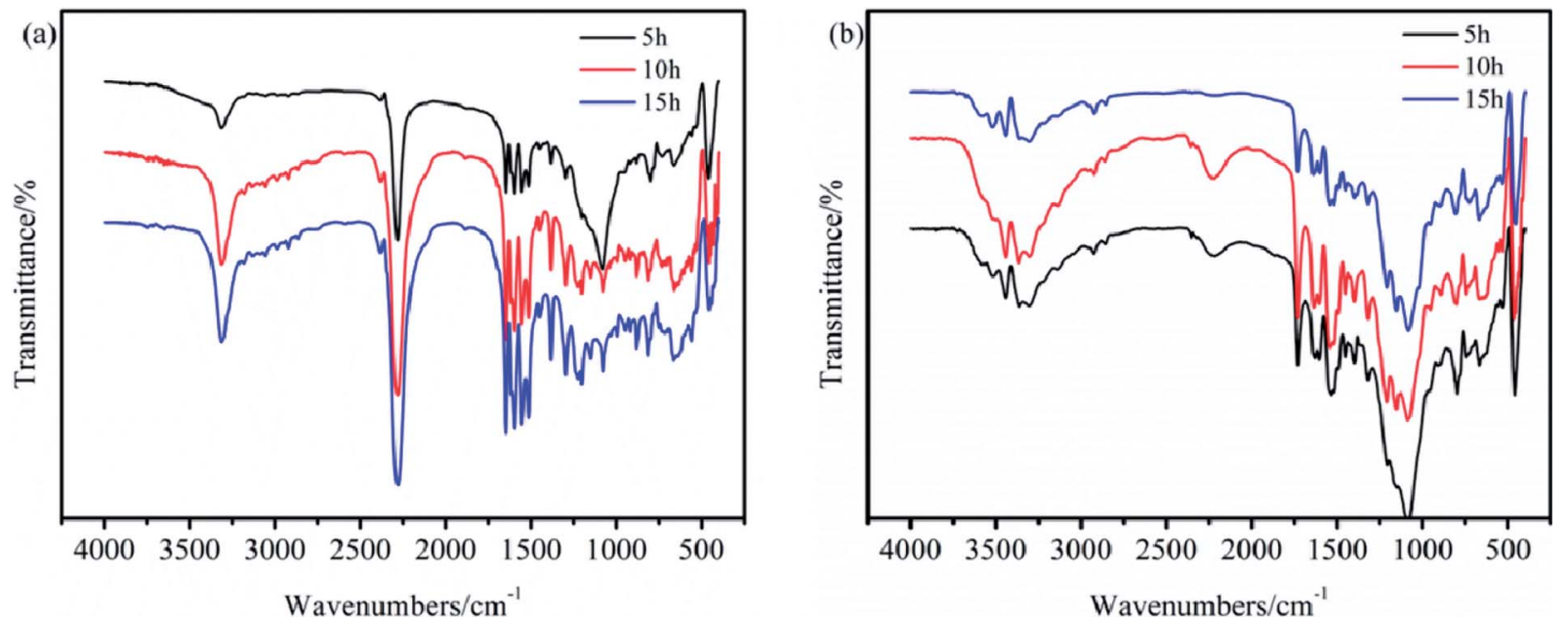

Fig. 5 IR spectra of (a) TB prepared at $50{ }^{\circ} \mathrm{C}$ and (b) TTB prepared at $40{ }^{\circ} \mathrm{C}$ for different times. 


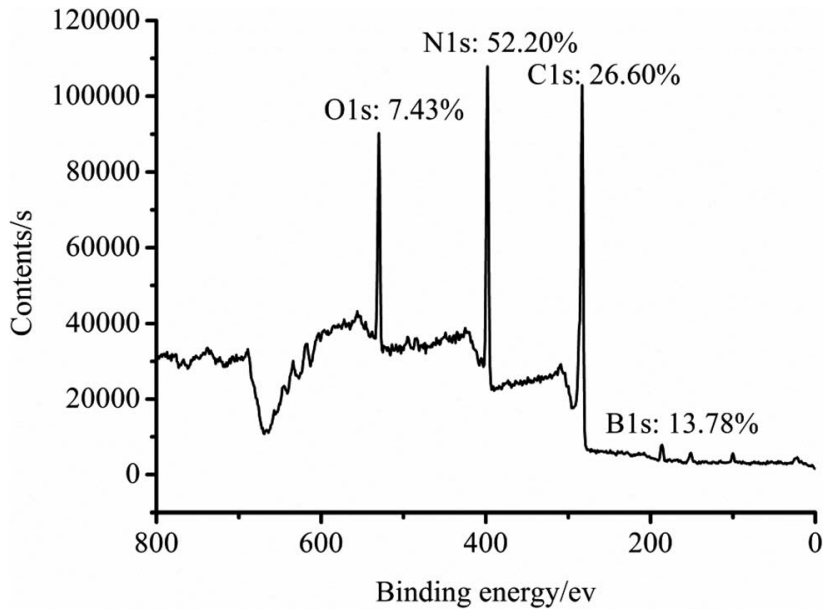

Fig. 6 XPS spectrum of the TTB prepared at the optimized reaction conditions.

B-O bond in the suboxide $\left(\mathrm{B}_{x}-\mathrm{O}\right)$ strengthened, resulting from the acidification and oxidation with nitric acid. In Table 1, in the XPS spectrum of the TTB, the $\mathrm{N}$ content was higher than that of the $\mathrm{TB}$, which was caused by the incorporation of $\mathrm{N}$ from the ATZ into the TTB particles. The $\mathrm{N}$ content of TB prepared at $50{ }^{\circ} \mathrm{C}$ was obviously higher than that prepared at $70{ }^{\circ} \mathrm{C}$ and $90{ }^{\circ} \mathrm{C}$, and the $\mathrm{N}$ content of TTB prepared at $40{ }^{\circ} \mathrm{C}$ was also obviously higher than that prepared at $60{ }^{\circ} \mathrm{C}$ and $80^{\circ} \mathrm{C}$. Thus, the reactions are sensitive to the temperature conditions, and $50{ }^{\circ} \mathrm{C}$ and $40{ }^{\circ} \mathrm{C}$ are appropriate to the carbamation and the ureylene addition reactions, respectively.

Herein, the reaction time was further investigated using IR spectroscopy to confirm the compositions of TB and TTB. The IR spectra of TB prepared at $50{ }^{\circ} \mathrm{C}$ for 5,10 , and $15 \mathrm{~h}$ and TTB prepared at $40{ }^{\circ} \mathrm{C}$ with $\mathrm{TB}$ prepared at $50{ }^{\circ} \mathrm{C}$ for $10 \mathrm{~h}$ as the raw material are shown in Fig. 5. The bands at 3305, 2276, 1740 and $1596 \mathrm{~cm}^{-1}$ corresponding to the $\mathrm{N}-\mathrm{H}$ of-NH-COO-, $\mathrm{N}=\mathrm{C}=\mathrm{O}$,
$\mathrm{C}=\mathrm{O}$ of $-\mathrm{NH}-\mathrm{CO}-\mathrm{N}^{\prime}$ and benzene ring were easily distinguished. The absorption frequencies from the reaction times of 5,10 , and $15 \mathrm{~h}$ were nearly equal. This indicates that along with the extended reaction time, the $-\mathrm{NH}-\mathrm{COO}-, \mathrm{N}=\mathrm{C}=\mathrm{O}$ and $-\mathrm{NH}-\mathrm{CO}-\mathrm{N}^{\prime}$ groups are chemically stable, so a $5 \mathrm{~h}$ reaction time is appropriate for the preparation of both TB and TTB.

After optimizing the reaction conditions, conditions of temperature of $50{ }^{\circ} \mathrm{C}$ for $5 \mathrm{~h}$ in the preparation of $\mathrm{TB}$, and $40{ }^{\circ} \mathrm{C}$ for $5 \mathrm{~h}$ in the preparation of TTB were proven as the improved reaction conditions. Finally, the target material TTB was prepared at the optimized conditions mentioned above, and the resulting XPS spectrum and elemental content are shown in Fig. 6. The $\mathrm{N}$ content of the particle surface is $52.2 \%$ in the target material TTB, which is likely beneficial to improve the impulse of the energetic boron powder and its composites.

\subsection{Solid-state ${ }^{13} \mathrm{C}-\mathrm{NMR}$ analysis}

Solid-state ${ }^{13} \mathrm{C}-\mathrm{NMR}$ spectrometry was carried out, and the results for the TB and TTB are shown in Fig. 7. In Fig. 7a, the peak signals at 17.4, 134.1, and $155.7 \mathrm{ppm}$ came from the $-\mathrm{CH}_{3}$ (C-3), unreacted - NCO (C-1) and the carbamate group (-NHCOO-, C-2) of TB molecule, respectively. ${ }^{22}$ The peaks at 137.1, $136.4,130.7,119.8,118.4$, and $115.9 \mathrm{ppm}$ could be respectively assigned to the C-7, 5, 9, 4, 8, and 6 in the benzene ring of TB molecule as shown in the insert figure of Fig. $7 a .^{22}$ In Fig. $7 b$, the peak at $19.6 \mathrm{ppm}$ was the signal of the $-\mathrm{CH}_{3}$ (C-3) of TTB molecule. The signals from the carbon adjacent to the carbamate group (-NH-COO-, C-2) and urea group (-NH-CO-N', $\mathrm{C}-1)$ both appeared approximately at $157.5 \mathrm{ppm}$. The peak at 147.5 ppm was the signal of $>\mathrm{N}-\mathrm{CH}=\mathrm{N}$ - carbon in the triazole of the ATZ, ${ }^{23}$ indicating that the ATZ molecule has been successfully introduced to the modified boron powders. The peak at 135.8 ppm was assigned to the C-7 and 5 in the benzene ring linked with the carbamate and urea groups of TTB molecule. The other peaks at 130.6, 128.0, 122.9, and 119.8 ppm were
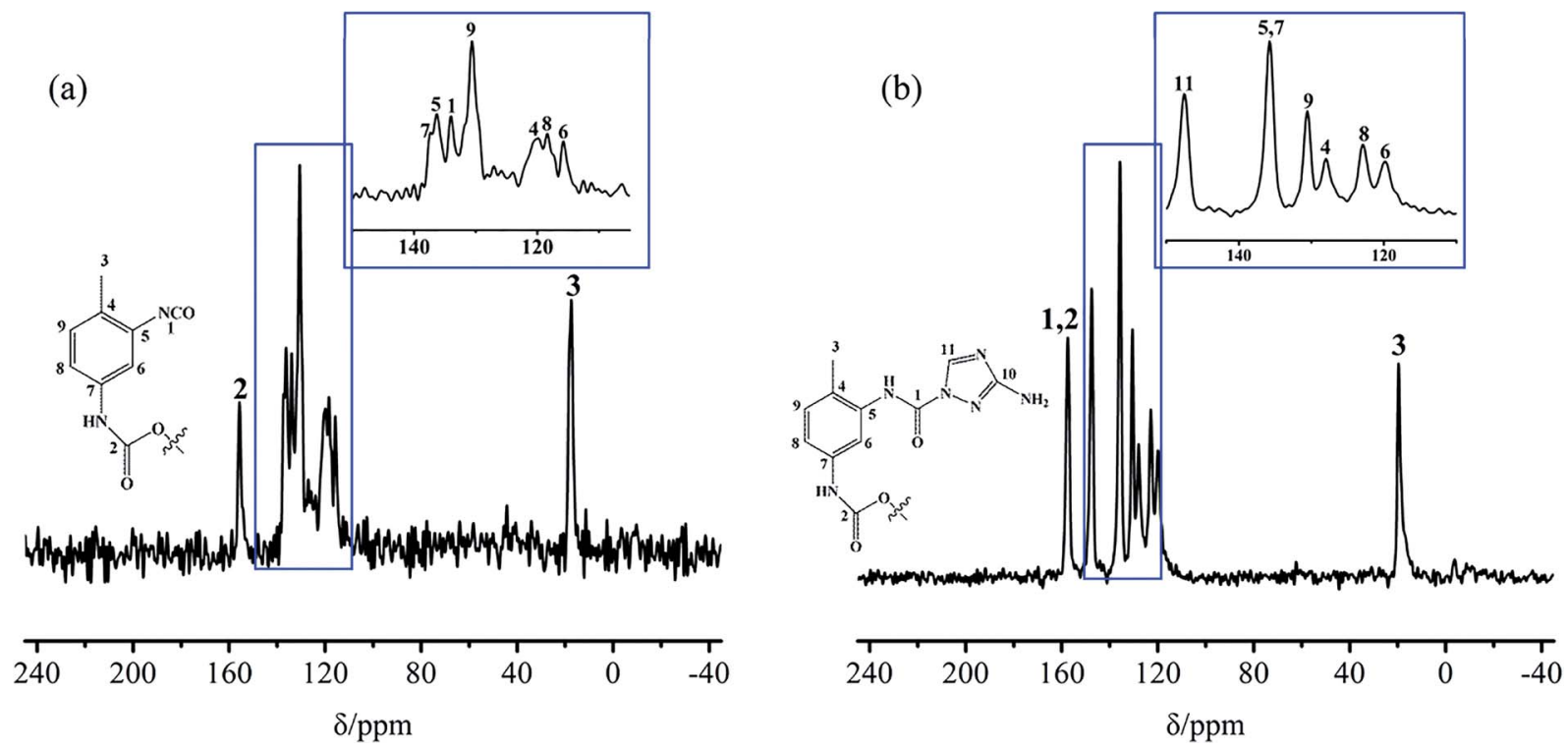

Fig. $7{ }^{13} \mathrm{C}-\mathrm{NMR}$ of (a) TB and (b) TTB. 

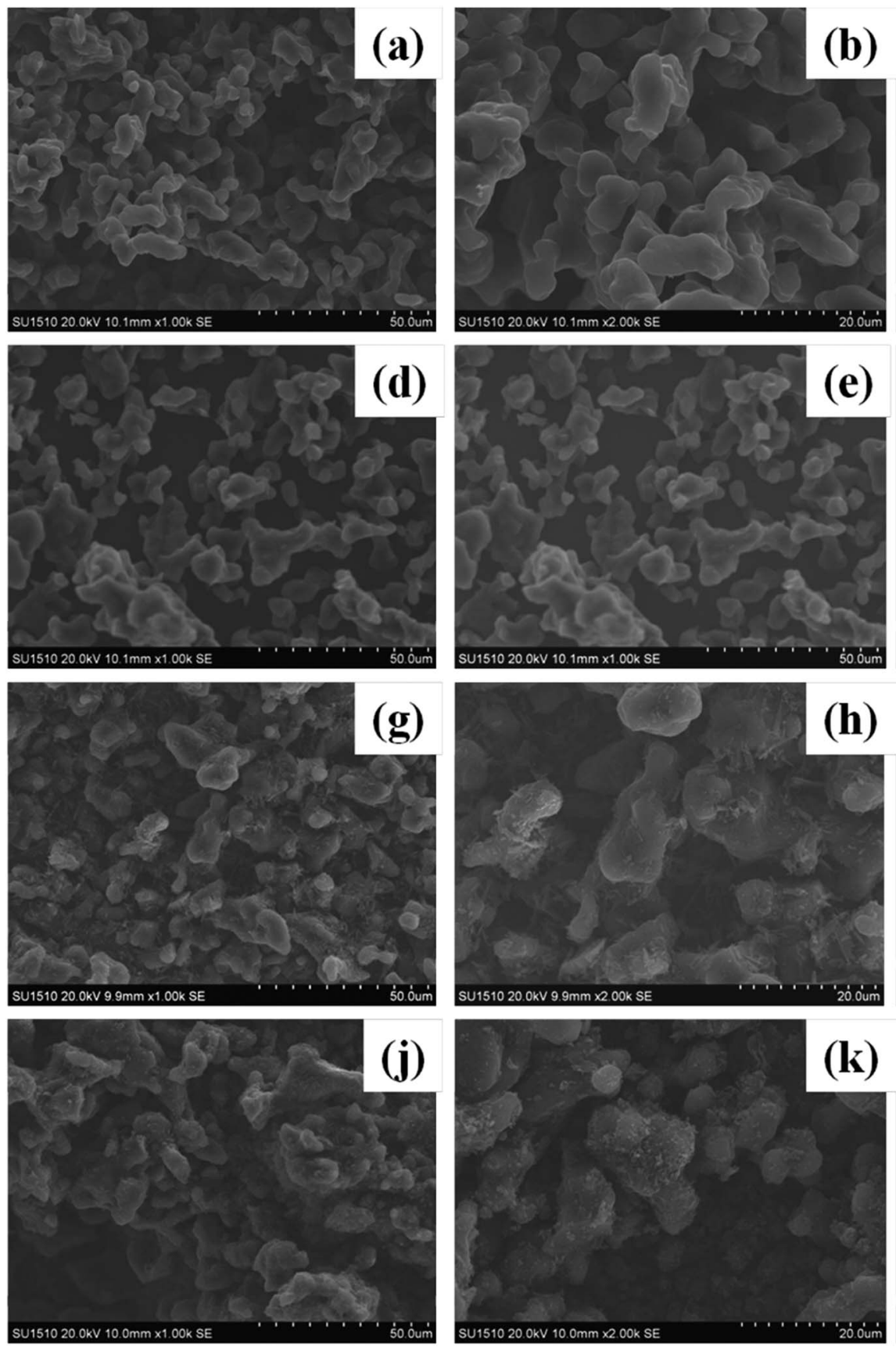
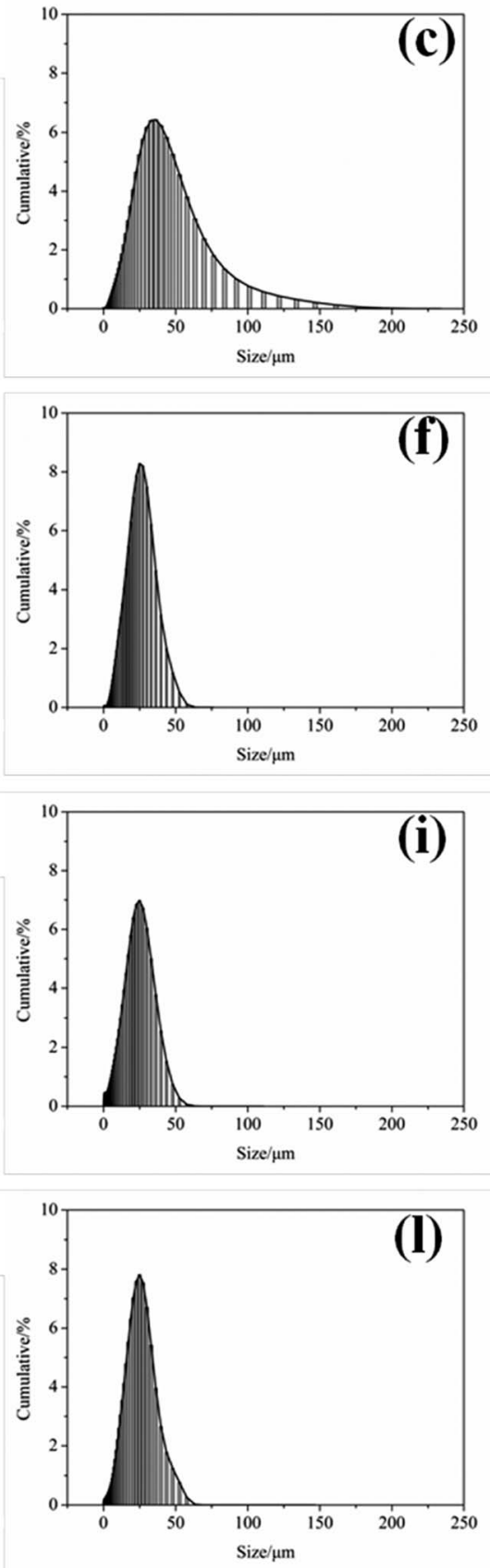

Fig. 8 SEM images and size distribution for $(a-c) E B$, (d-f) AB, $(g-i) T B$, and $(j-l)$ TTB.

the signals of C-9, 4, 8, and 6 in the benzene ring. There was no additional peak attributed to the quaternary carbon atom of C$\mathrm{NH}_{2}$ in ATZ, possibly because its longer relaxation time or change of electronic state produced by charge transfer made the signal missing. ${ }^{27,28}$ The IR spectra and NMR spectra analyses for the TB and TTB illustrate that a novel covalently bonded energetic boron powder has been successfully prepared.

\subsection{SEM and TEM micrographs of the samples}

The surface morphology of $\mathrm{EB}, \mathrm{AB}, \mathrm{TB}$ and TTB was studied with SEM and shown in Fig. 8. As seen from Fig. 8a-b, d-e, the particle surface of the raw material $\mathrm{EB}$ and intermediate $\mathrm{AB}$ is glossy. After carbamation of $\mathrm{AB}$, the particle surface of the intermediate ТВ became coarse with some flake substance adhering to the surface, which was caused by the grafted TDI molecules. In the last modification step, the TDI molecules on the surface reacted with ATZ, so the former flake substance was transferred to tiny particles to form a tight coating layer.

The particle size distribution of the four samples was also presented in Fig. 8, and the median particle size of $\mathrm{EB}, \mathrm{AB}, \mathrm{TB}$ and TTB was 33.3, 22.6, 19.7 and $21.5 \mu \mathrm{m}$, respectively. After acidification, the particle size significantly reduced, because the 

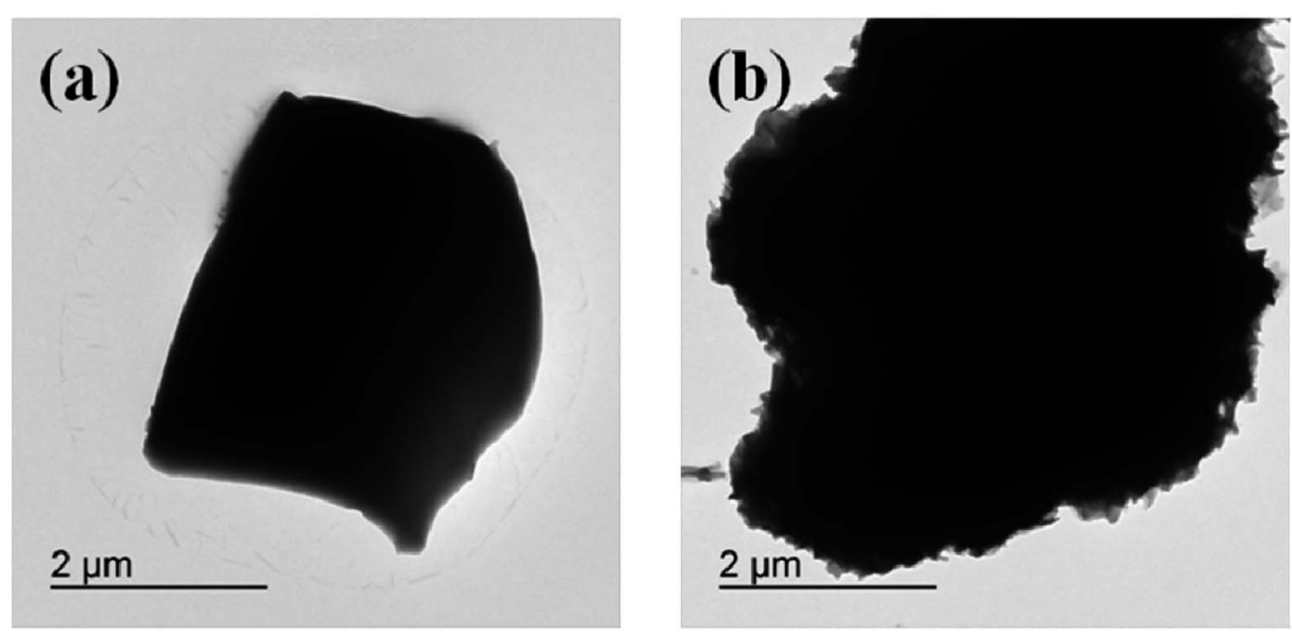

Fig. 9 TEM images of the boron powders for (a) EB and (b) TTB.

surface $\mathrm{B}_{2} \mathrm{O}_{3}$ reacted with water in the nitric acid and acetone solvent. The particle size of TB and TTB was a little smaller than that of $\mathrm{AB}$, possibly owing to the mass loss of ultrafine particles in the filtration. Different from the particle size by laser particle size analysis, the particle size of TB in SEM micrographs seemed larger than others, because the unreacted -NCO groups on the surface have strong interaction with other particles, and then TB particles tended to reunite.

To further verify the morphological change before and after the chemical modification, the morphologies of the EB and TTB were studied using TEM. As is shown in Fig. 9, it is obvious that the surface of the TTB particles is rougher, which is probably caused by the organic coating layer.

\subsection{Static water contact angle on the boron surface}

The changes in the surface properties of the boron powders after chemical modification are also accompanied by changes in the surface energy. The static water contact angle on the surface of the $\mathrm{EB}, \mathrm{AB}, \mathrm{TB}$ and $\mathrm{TTB}$ were measured, and the results are given in Fig. 10. It is clearly seen from Fig. 10a-b that water can easily permeate the surface of the boron powders $\mathrm{EB}$ and $\mathrm{AB}$, giving a static water contact angle of $0^{\circ}$ for both. After the surface was grafted with TDI molecules, the water drop could steadily stay on the surface of the TB pellet, as shown in Fig. 10c, with a static water contact angle of $148.3^{\circ}$. In conclusion, the surface properties of the boron powders are significantly changed from hydrophilic to hydrophobic after grafting with the nonpolar TDI molecules owing to the highly nonpolar benzene ring and the methyl group. After the ureylene addition between the TB and the polar molecule ATZ due to the numerous $\mathrm{N}$ atoms and amino groups, the surface properties of the TTB boron powders were changed to be more polar than the $\mathrm{TB}$, and the static water contact angle was $37.0^{\circ}$.

\subsection{Rheological property}

Rheological characterization is important for boron powders in hydroxyl-terminated polybutadiene (HTPB), a widely used binder of solid propellants and cast cured explosives. ${ }^{29}$ In our work, the rheological property of HTPB containing $30 \%$ boron powers heating at $70{ }^{\circ} \mathrm{C}$ for different time were tested by a rheometer. Fig. 11a showed the relationship between the viscosity and shear rate at the beginning of heating. The results showed that the viscosity of EB/HTPB was nearly constant at 6.7-9.3 Pa s with an increase in shear rate, but the viscosity of TTB/HTPB decreased from $163 \mathrm{~Pa}$ s to $5.8 \mathrm{~Pa}$ s. As shown in Fig. 11b, after heating at $70{ }^{\circ} \mathrm{C}$ for 10 hours, the viscosity of EB/ HTPB was also constant at 6.8-9.3 Pa s, which was equal with that before heating. While the viscosity of TTB/HTPB sustained at 4.5-5.1 Pa s, indicating that the mixture became to a Newtonian fluid. It was inferred that, at the beginning of heating, TTB/HTPB owned a higher viscosity, due to the ragged coating layer of TTB, and after heating for a long time, the viscosity of TTB/HTPB decreased because of the excellent infiltration between the polar grafting molecular ATZ with HTPB. (a)

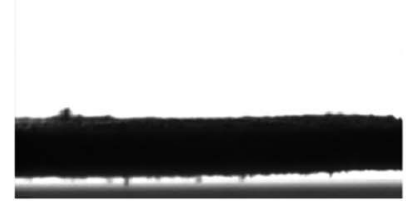

(b)

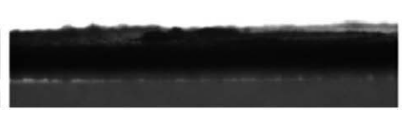

(c)

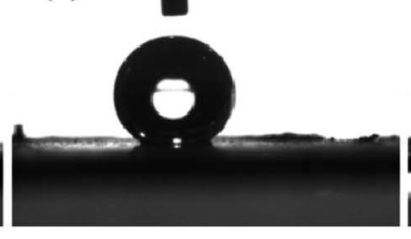

(d)

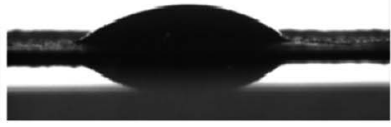

Fig. 10 Images of a water droplet sitting on the surface of the (a) EB, (b) AB, (c) TB, and (d) TTB. 

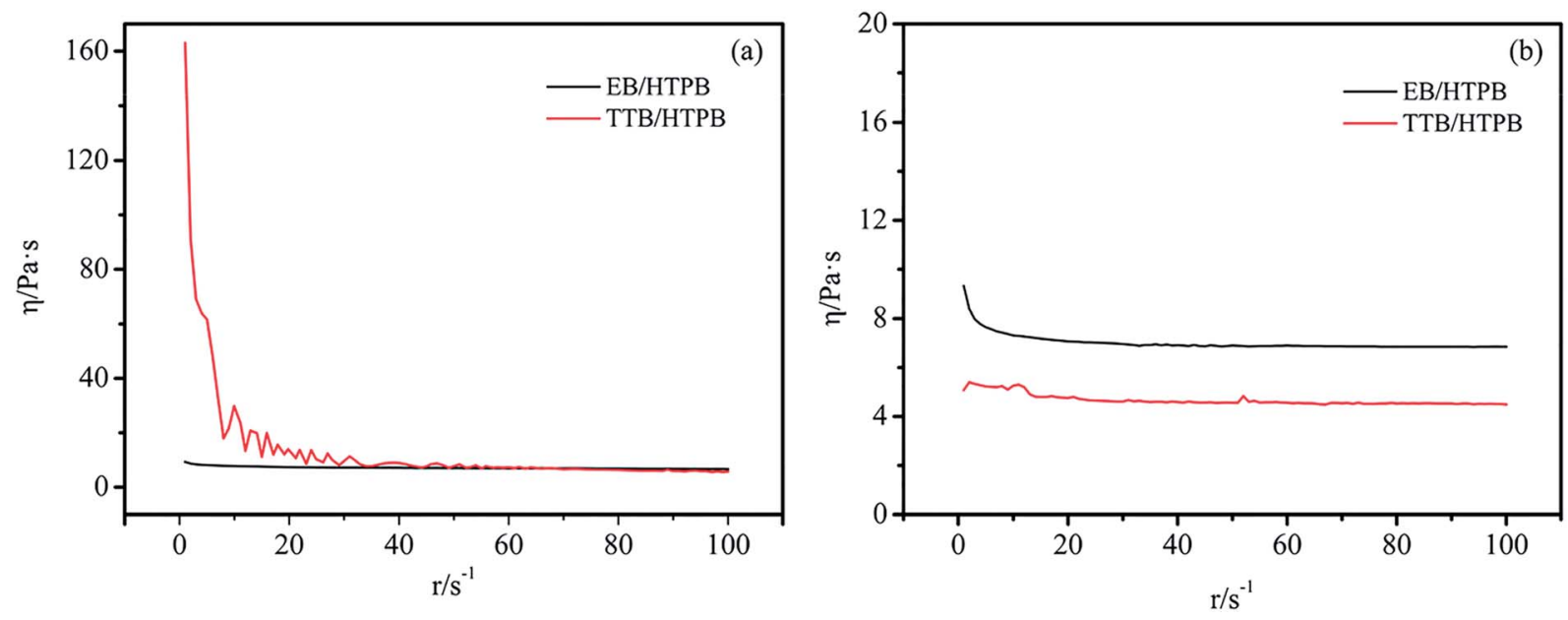

Fig. 11 Viscosity of B/HTPB heating at $70{ }^{\circ} \mathrm{C}$ for (a) $0 \mathrm{~h}$, (b) $10 \mathrm{~h}$.

Therefore, the energetic boron powders with a strategy of covalent bonding on particle surface, would not deteriorate the dispersion and processing properties.

\subsection{Thermal stability of TB and TTB}

To determine the thermal stability of TB and TTB in a nitrogen atmosphere from room temperature to $1200{ }^{\circ} \mathrm{C}$, simultaneous thermogravimetry/differential scanning calorimetry (TG/DSC) measurements were taken, and the results are given in Fig. 12. As shown in Fig. 12a, there are two weak endothermic peaks appearing at $192{ }^{\circ} \mathrm{C}$ and $304{ }^{\circ} \mathrm{C}$ in the DSC curve, and the weight loss of TB began from $189^{\circ} \mathrm{C}$ and ended at $342{ }^{\circ} \mathrm{C}$, with a total weight loss of $7.1 \%$. This process can be assigned to the decomposition of the TDI group on the surface of the TB particles. In Fig. 12b, three weak endothermic peaks located at 245,283 and $329^{\circ} \mathrm{C}$ can be found in the DSC curve. The weight loss of the TTB began from $198{ }^{\circ} \mathrm{C}$ to $375^{\circ} \mathrm{C}$ with a total weight loss $8.4 \%$. The TTB has a higher weight loss ratio due to the introduction of the ATZ molecule based on the TB powders. The results show that both TB and TTB are thermally stable, which is convenient for the preparation, storage and usage of the target material TTB and its key intermediate product TB.

\subsection{Thermal reaction of the $\mathrm{B} / \mathrm{KNO}_{3}$ composites}

To investigate the reaction activities of boron powders before and after the modification, the composites $\mathrm{EB} / \mathrm{KNO}_{3}$ and TTB/ $\mathrm{KNO}_{3}$ were prepared as well-known pyrotechnics. TG/DSC was used to characterize their thermo-reaction properties. From the DSC curves shown in Fig. 13, the heat releasing reaction of the $\mathrm{TTB} / \mathrm{KNO}_{3}$ mainly occurred at the peak temperature of $450{ }^{\circ} \mathrm{C}$ and was assigned to their oxidation-reduction reaction, which occurred at $30{ }^{\circ} \mathrm{C}$ earlier than that of $\mathrm{EB} / \mathrm{KNO}_{3}$ with a predominant exothermic peak at $480{ }^{\circ} \mathrm{C}$. In the TG curves, the tiny endothermic peaks at $138{ }^{\circ} \mathrm{C}$ and $338^{\circ} \mathrm{C}$ were assigned to the rhombic to trigonal crystalline phase transition and melting of $\mathrm{KNO}_{3} \cdot{ }^{30}$ The weight loss began at $430{ }^{\circ} \mathrm{C}$ for the $\mathrm{EB} / \mathrm{KNO}_{3}$ and $200{ }^{\circ} \mathrm{C}$ for the $\mathrm{TTB} / \mathrm{KNO}_{3}$, which can be attributed to the continuous decomposition of the organic layer and the oxidation-reduction reaction between the boron and potassium nitrate starting from $400{ }^{\circ} \mathrm{C}$. Both the TG and DSC curves
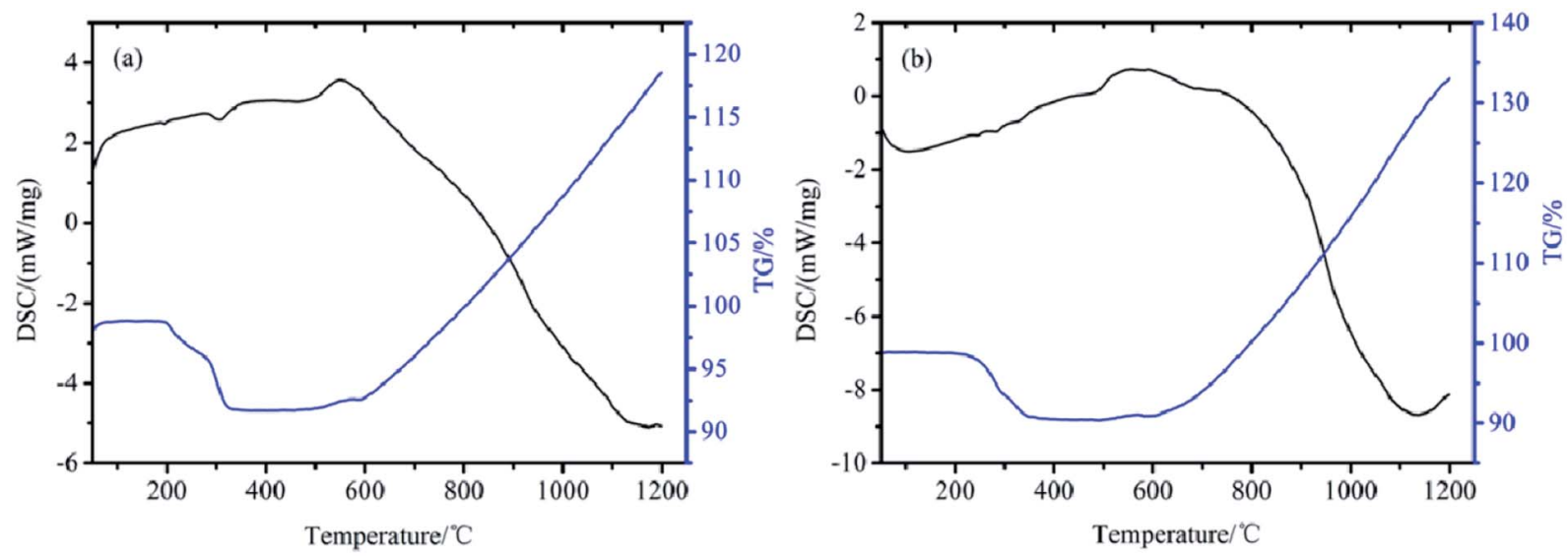

Fig. 12 TG/DSC curves of (a) TB and (b) TTB. 

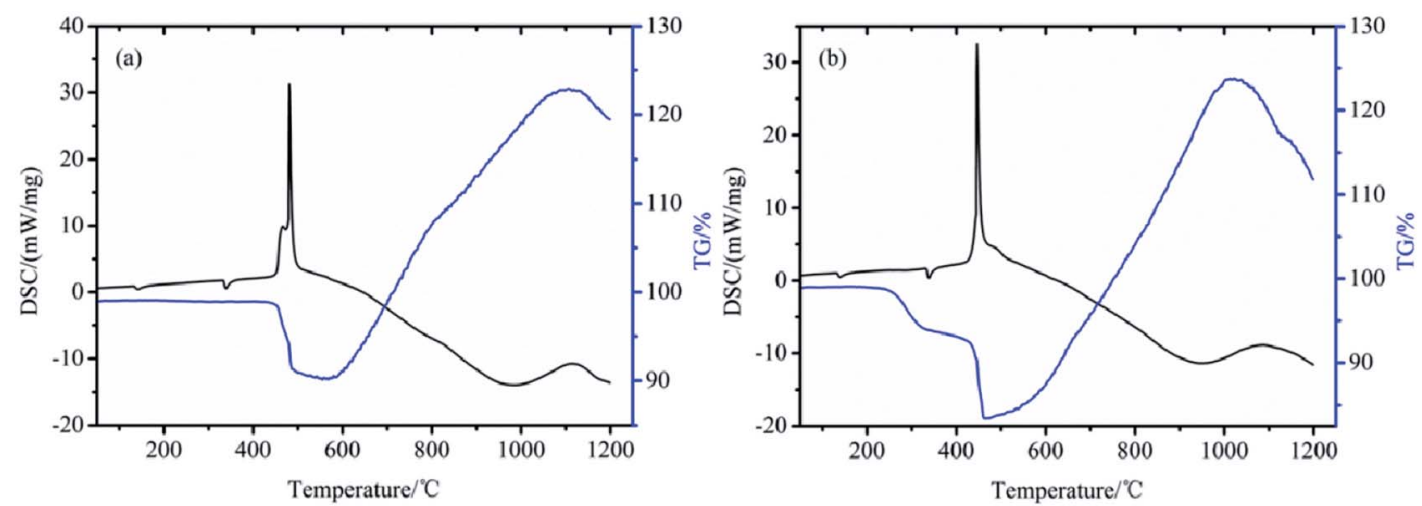

Fig. $13 \mathrm{TG} / \mathrm{DSC}$ curves of (a) $\mathrm{EB} / \mathrm{KNO}_{3}$ and (b) $\mathrm{TTB} / \mathrm{KNO}_{3}$.

indicate that the usage of the covalent bonded energetic boron powders is beneficial to reduce the critical reaction temperature of the pyrotechnics $\mathrm{B} / \mathrm{KNO}_{3}$ composites and improve the ignition of the boron powders. In our work, the grafting modification on the boron particle surface with energetic molecule was more efficient to reduce the critical reaction temperature of boron-potassium nitrate pyrotechnic charge than the previous research, in which cellulosic binders, phenolic resin and RDX or HMX were mixed physically. ${ }^{31}$

\section{Conclusion}

In conclusion, we developed a new kind of covalently bonded energetic boron powder with improved ignition properties in $\mathrm{B} /$ $\mathrm{KNO}_{3}$ used as pyrotechnics. The reaction conditions predominantly affect the chemical structure of the modified boron powders and the stability of the isocyanate reaction sites. The small organic molecules are grafted on the boron surface through covalent bonds. The covalently bonded energetic boron powders enable the pyrotechnic $\mathrm{B} / \mathrm{KNO}_{3}$ to react at a lower critical temperature. This approach gives a new method to prepare highly energetic boron powders, which can be widely used in propellants, explosives and pyrotechnics.

\section{Conflicts of interest}

There are no conflicts to declare.

\section{Acknowledgements}

Financial support from the National Natural Science Foundation of China (No. 11502249, 11572359, 11502248) is gratefully acknowledged.

\section{References}

1 (a) V. Pepekin, Int. Annu. Conf. ICT, 1996, vol. V19; (b) A. Maranda, Propellants, Explos., Pyrotech., 1990, 4, 161165; (c) H. Ghassemi and H. F. Fasih, Aerosp. Sci. Technol., 2013, 1, 1-8.
2 (a) Z. Chen and R. Yang, J. Propul. Technol., 1998, 1, 102-106; (b) W. Pang and X. Fan, Chem. Propellants Polym. Mater., 2009, 2, 1-5.

3 N. H. Yen and L. Y. Wang, Propellants, Explos., Pyrotech., 2012, 2, 143-155.

4 C. Rossi, K. Zhang, D. Estève, P. Alphonse, P. Tailhades and C. Vahlas, J. Microelectromech. Syst., 2007, 4, 919-931.

5 J. Xi, J. Liu, H. Li, Y. Wang, Y. Zhang, J. Zhou and K. Cen, Chin. J. Energ. Mater., 2013, 4, 533-538.

6 R. M. Adams, J. Am. Chem. Soc., 1965, 15, 3535-3536.

7 (a) M. N. Makhov, Russ. J. Phys. Chem. B, 2015, 1, 50-55; (b) S. Xu, Yu. Chen, X. Chen, D. Wu and D. Liu, Combust., Expl., Shock Waves, 2016, vol. 3, pp. 342-349.

8 (a) W. Zhang, H. Zhu and D. Fang, Chin. J. Energ. Mater., 1998, 4, 179-186; (b) R. W. Conner and D. D. Dlott, J. Phys. Chem. C, 2012, 116, 2751-2760.

9 (a) D. J. Erskine, L. Green and C. Tarver, The American physical society topical conference on shock compression of condensed matter, Albuquerque, 1989; (b) C. M. Tarver, 14th APS Topical Conference on SCCM, 2005.

10 (a) A. Macek and J. Semple, Combust. Sci. Technol., 1969, 3, 181-191; (b) C. L. Yeh and K. K. Kuo, Prog. Energy Combust. Sci., 1996, 6, 511-541; (c) G. Young, K. Sullivan, M. R. Zachariah and K. Yu, Combust. Flame, 2009, 2, 322333.

11 (a) D. Guan and N. Wang, Chin. J. Explos. Propellants, 1998, 2, 52-54; (b) M. A. Trunov, V. K. Hoffmann, M. Schoenitz and E. L. Dreizin, Journal of Propulsion Powder, 2012, 2, 184-191.

12 (a) J. C. Trowbridge and J. D. Breazeale, US pat. 4877649, 1989; (b) I. M. Shyu and T. K. Liu, Combust. Flame, 1995, 4, 634-644.

13 H. Li, X. Wan, X. Gao and J. Li, China Ceram., 2008, 8, 10-12. 14 S. He and B. Liu, Mater. Res. Appl., 2016, 2, 71-74.

15 (a) S. Thoru, I. Masahiro, N. Toshihiko and T. Naoe, EP328906 A2, 1989; (b) R. Wolfgang and S. Guenter. US pat. 5332767, 1994.

16 J. Wang, G. Xu, X. Ji and R. Gong, Chin. J. Inorg. Chem., 2003, 9, 967-970.

17 W. Ma and A. Dong, Electron. Compon. Mater., 2006, 5, 62-64. 18 G. Yuan and S. Su, J. Dispersion Sci. Technol., 2010, 31, 327331. 
19 Z. Gao, N. I. Walton, A. Malugin, H. Ghandehari and I. Zharov, J. Mater. Chem., 2012, 22, 877-882.

20 R. J. P. Lima, C. Dubois, O. Mader, R. Stowe and S. Ringuete, Int. J. Energ. Mater. Chem. Propul., 2010, 5, 437-446.

21 H. Xue, Y. Gao, B. Shreeve and J. M. Shreeve, Inorg. Chem., 2005, 14, 5068-5072.

22 (a) R. Lu, B. Qian, H. Deng and H. Yang, Chin. J. Chem., 1997, 6, 541-547; (b) M. Lesar, M. Žigon and T. Malavašič, J. Appl. Polym. Sci., 1993, 5, 805-814; (c) H. Han, S. Li, X. Zhu, $\mathrm{X}$. Jiang and X. Kong, $R S C$ Adv., 2014, 4, 33520-33529.

23 (a) T. Hirata, L. Twanmoh, H. Wood Jr, A. Goldin and J. Driscoll, J. Heterocycl. Chem., 1972, 1, 99-106; (b) G. Chipen, R. Bokaldere and V. Grinshtein, Chem. Heterocycl. Compd., 1971, 4, 546-547; (c) J. Reiter, L. Pongó and P. Dvortsák, J. Heterocycl. Chem., 1987, 6, 1685-1695; (d) T. Winkler and H. Kristinsson, Helv. Chim. Acta, 1983, 2, 694-700; (e) Y. L. Duc, E. Licsandru, D. Vullo, M. Barboiu and C. T. Supuran, Bioorg. Med. Chem., 2017, 5, 1681-1686.

24 (a) C. Ronning, D. Schwen, S. Eyhusen, U. Vetter and H. Hofsass, Surf. Coat. Technol., 2002, 158, 382-387; (b) A. Jain, S. Anthonysamy, K. Ananthasivan, R. Ranganathan, V. Mittal, S. V. Narasimhan and P. R. Vasudeva Rao, Mater. Charact., 2008, 7, 890-900.

25 (a) W. Moddeman, A. Burke, W. Bowling and D. Foose, Surf. Interface Anal., 1989, 14, 224-232; (b) M. Ennaceur and B. Terreault, J. Nucl. Mater., 2000, 280, 33-38; (c) T. Xu,
J. Zheng, N. Wu, A. Nicholls, J. Roth, D. Dikin and R. Ruoff, Nano Lett., 2004, 5, 963-968; (d) W. Foo, J. Ozcomert and M. Trenary, Surf. Sci., 1991, 255, 245-258.

26 (a) D. Hendrickson, J. Hollander and W. Jolly, Inorg. Chem., 1970, 3, 612-615; (b) J. Schreifels, P. Maybury and W. Swartz, J. Catal., 1980, 65, 195-206.

27 (a) M. TrewhellaIain, J. Poplett and A. Grin, Fuel, 1986, 4, 541-546; (b) G. A. Nagana Gowda, Magn. Reson. Chem., 2001, 10, 581-585; (c) S. Barbuceanu, G. Saramet, G. Almajan, C. Draghicic, F. Barbuceanu and G. Bancescu, Eur. J. Med. Chem., 2012, 49, 417-423.

28 (a) H. Chen and Q. Shao, J. Instrum. Anal., 1995, 6, 21-25; (b) F. J. Dinan, W. T. Schwartz, R. A. Wolfe, D. S. Hojnicki, T. St. Clair and J. Richard Pratt, J. Polym. Sci., Part A-1: Polym. Chem., 1992, 1, 111-118; (c) R. Foster, J. Iball, S. N. Scrimgeour and B. C. Williams, J. Chem. Soc., Perkin Trans. 2, 1976, 6, 682-685.

29 (a) R. Manjari, V. C. Joseph, L. P. Pandureng and T. Sriram, J. Appl. Polym. Sci., 1993, 2, 271-278; (b) P. P. Vadhe, R. B. Pawar, R. K. Sinha, S. N. Asthana and A. Subhananda Rao, Combust., Expl., Shock Waves, 2008, vol. 4, pp. 461-477. 30 R. Rugunanan and M. Brown, J. Therm. Anal. Calorim., 1991, 37, 1193-1211.

31 (a) V. Bhingarkar and H. Singh, Def. Sci. J., 2006, 3, 345-351; (b) K. Krishnan, R. Ammal, B. Hariharanath, A. Rajendran and C. Kartha, Def. Sci. J., 2006, 3, 329-338; (c) Y. Ye, L. Shu and R. Shen, Chin. J. Energ. Mater., 2007, 1, 33-35. 